\title{
Erratum
}

\section{An algorithmic approach to the number of spanning trees in Buckminsterfullerene}

[J. Math. Chem. 15(1994) 261-271]

\author{
P.E. John \\ Institut für Mathematik, Technische Hochschule, Ilmenau, PSF 327, \\ D-98684 Ilmenau/Thür., Germany \\ R.B. Mallion \\ The King 's School, Canterbury, Kent, CT1 2ES, England, UK
}

Received 18 August 1994

The number of spanning trees in Buckminsterfullerene reported [1] was correct when expressed as powers of prime numbers, i.e.,

$$
2^{25} \times 3^{4} \times 5^{3} \times 11^{5} \times 19^{3}
$$

but there was, unfortunately, an undetected mis-print in the 21-digit number claimed in [1] to be the equivalent of the above; the $12^{\text {th }}$ figure of this integer should be ' 2 ', rather than the ' 3 ' unintentionally alleged in ref. [1]. Thus, the spanningtree count of the $\mathrm{C}_{60}$ molecular-graph quoted on page 268 of [1] as being

$37529186637 \underline{3} 898816000$,

should in fact have been

$37529186637 \underline{2} 898816000$.

This agrees (as claimed in [1]) with the previously reported value [2] of the complexity of Buckminsterfullerene, as well as with five other subsequent, and independently calculated, estimates of it [3-5].

\section{References}

[1] P.E. John and R.B. Mallion, J, Math. Chem. 15(1994) 261.

(C) J.C. Baltzer AG, Science Publishers 
[2] T.J.N. Brown, R.B. Mallion, P. Pollak, B.R.M. de Castro and J.A.N.F. Gomes, J. Comput. Chem. 12(1991) 1118.

[3] Z. Mihalić and N. Trinajstić, Fullerene Science \& Technology, in press.

[4] N. Trinajstić, Z. Mihalić and F.E. Harris, Int. J. Quant. Chem. Quant. Chem. Symp., submitted for publication.

[5] T.J.N. Brown, R.B. Mallion, P. Pollak and A. Roth, Discrete Math., in press. 